\title{
Drought alters the spatial distribution, grazing patterns, and radula morphology of a fungal-farming salt marsh snail
}

\author{
B. Chalifour ${ }^{1,2, *}$, J. R. H. Hoogveld ${ }^{3}$, M. Derksen-Hooijberg ${ }^{3}$, \\ K. L. Harris ${ }^{4}$, J. M. Urueña ${ }^{4}$, W. G. Sawyer ${ }^{4,5,6}$, T. van der Heide ${ }^{3,7,8}$, C. Angelini ${ }^{9}$ \\ ${ }^{1}$ Department of Natural Resources and the Environment, University of Florida, PO Box 116455, Gainesville, FL 32611, USA \\ ${ }^{2}$ Department of Ecology and Evolutionary Biology, University of Colorado Boulder, 34 UCB, Boulder, CO 80309, USA \\ ${ }^{3}$ Department of Aquatic Ecology and Environmental Biology, Radboud University, 6525 AJ Nijmegen, The Netherlands \\ ${ }^{4}$ Department of Mechanical and Aerospace Engineering, University of Florida, 231 MAE-A, PO Box 116250, Gainesville, FL 32611, USA \\ ${ }^{5}$ Department of Materials Science and Engineering, University of Florida, 231 MAE-A, PO Box 116250, Gainesville, FL 32611, USA \\ ${ }^{6}$ J. Crayton Pruitt Family Department of Biomedical Engineering, University of Florida, 231 MAE-A, PO Box 116250, \\ Gainesville, FL 32611, USA \\ ${ }^{7}$ Department of Coastal Systems, Royal Netherlands Institute of Sea Research and Utrecht University, 1790 AB Den Burg, the Netherlands \\ ${ }^{8}$ Conservation Ecology Group, Groningen Institute for Evolutionary Life Sciences, 9700 CC University of Groningen, the Netherlands \\ ${ }^{9}$ Environmental Engineering Sciences, Engineering School of Sustainable Infrastructure and Environment, \\ University of Florida, PO Box 116580, Gainesville, FL 32611, USA
}

\begin{abstract}
Climate change is altering consumerplant interactions in ecosystems worldwide. How consumers alter their spatial distribution, grazing activities, and functional morphology in response to climate stress can determine whether their effects on plants intensify or relax. Few studies have considered multiple consumer response metrics to elucidate the mechanisms underpinning the resulting changes in consumerplant interactions. Here, we tested how drought stress influences the interaction between the dominant consumer, the fungal-farming periwinkle snail Littoraria irrorata, and a foundational plant, cordgrass Spartina alterniflora, in a southeastern US salt marsh. In a 4 mo field experiment, we maintained moderate snail densities in mesh control chambers and clear plastic climate chambers that simulated drought by elevating temperatures and drying soils. Monitoring revealed that snails more often congregated on cordgrass stems than leaves in climate chambers than in controls. Image analyses indicated that this behavioral shift corresponded to snails inflicting shorter, but more numerous, fungal-infested scars on cordgrass leaves, and causing less plant damage in climate chambers than controls. Coincident with their net reduction in grazing, snails maintained longer radulae, whose central teeth were blunter and lateral teeth were sharper, in climate chambers compared to controls. These results suggest that under drought, snail radulae may experience less frictional wear and that, at intermediate densities, snail-cordgrass interactions relax. Together with prior research showing that at high densities, snails can denude cordgrass during drought, we conclude that con-
\end{abstract}

${ }^{*}$ Corresponding author: bridget.chalifour@colorado.edu

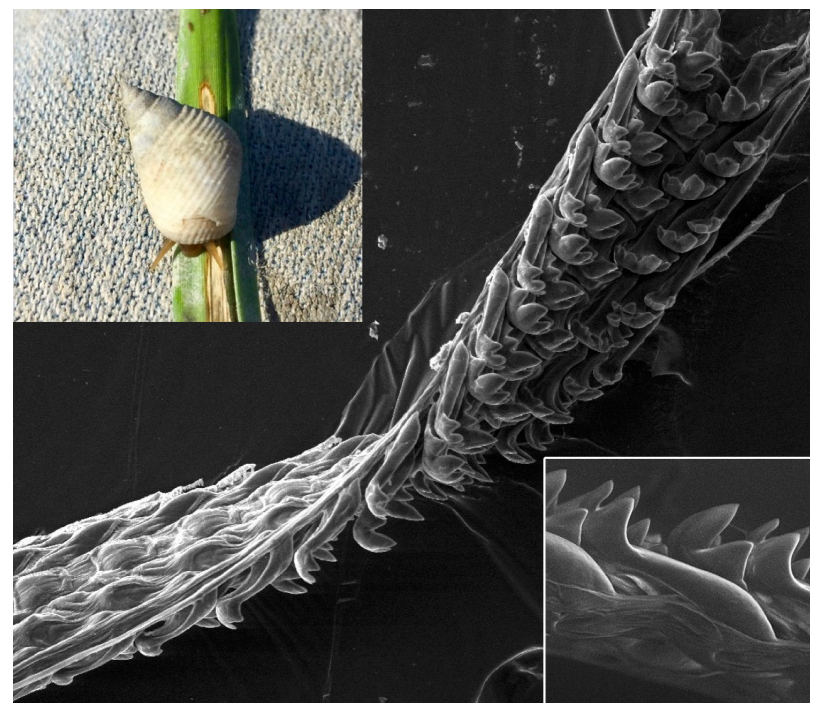

Saltmarsh snails (top left) stressed by drought conditions show reduced radula wear and shifts in tooth morphology (e.g. sharper lateral teeth; bottom right), suggesting that fewer resources are invested in maintaining the grazing apparatus. Climate change is expected to increase drought stress.

Images: K. L. Harris, C. Angelini

sumer density, behavior, and morphological responses must be integrated in predictions of how climate change will affect the direction, strength, and stability of consumer-plant interactions.

KEY WORDS: Climate change - Coastal wetland . Herbivory $\cdot$ Littoraria irrorata $\cdot$ Spartina alterniflora

(C) The authors 2019. Open Access under Creative Commons by Attribution Licence. Use, distribution and reproduction are unrestricted. Authors and original publication must be credited. 


\section{INTRODUCTION}

Consumer-plant interactions mediate energy transfer between autotrophs and heterotrophs and, as such, regulate patterns in plant production, community composition, and food web structure in nearly every ecosystem on earth (Polis \& Strong 1996, Agrawal 2001). The degree to which consumers shape plant assemblages depends on their ability to remove plant tissue either through direct consumption or their facilitation of bacteria and fungi that infect open wounds (Newell \& Barlocher 1993, Graca et al. 2000, Daleo et al. 2009). These actions require a consumer to bite, scrape, pierce, or otherwise damage a plant with its grazing apparatus. Reciprocally, plants shape consumer assemblages through the quantity and quality of nutritional resources they, and the microbes that infect their wounds, transfer to consumers (García-Guzmán \& Dirzo 2001). Both consumer grazing activities and plant defense mechanisms tend to be sensitive to environmental conditions, meaning that changes in the environment may alter the outcome of consumer-plant interactions (O'Connor 2009, Gilbert et al. 2014, He \& Silliman 2015). As the frequency, severity, and duration of episodes of intensive environmental stress increase with climate change (Millennium Ecosystem Assessment 2005), expanding our understanding of how and why the nature of consumer-plant interactions shifts in response and quantifying what the consequences may be for ecosystem structure and function has become an increasingly pressing challenge (He \& Silliman 2015).

How consumer-plant interactions respond to climatic stress depends on the functional response of both the consumer and plant (Berlow et al. 2004, Atkins et al. 2015). Consumers may decrease or increase their grazing activities and/or seek out refuges as environmental conditions become stressful. These behavioral adjustments are contingent on the consumer's mobility and sensitivity to stress and have the potential to alleviate top-down control in more stressful areas and intensify it in refuges (Menge \& Sutherland 1987). Simultaneously, plants may alter their chemistry, physiology, production of secondary compounds, and growth as conditions become hotter, drier, or otherwise more stressful-effects that can make it harder for grazers to damage them and/or for microbes to infect their wounds (Briske 1996). These include morphological adaptations such as the development of trichomes, spines, and waxy cuticles, along with protective proteins and enzymes induced chemically in the plant that deter grazers (War et al. 2012). For instance, rodents suppress shrub growth more strongly during drought because shrubs become limited in their ability to compensate for rodent grazing damage (Meserve et al. 2003). Similarly, corals often experience dieback during heat spells and nutrient blooms because these events physiologically stress corals and fuel microbial consumption of their tissues (Williams \& Miller 2005, Bruno et al. 2007).

Consumers, in turn, may alter the morphology of their grazing apparatus (e.g. teeth, mandibles, tongues) or experience more or less wear on these structures in response to climate change (Raia et al. 2010, Muschick et al. 2011). These morphological and wear responses to climate, which can be provoked by shifts in either the consumer's metabolic demand or in the difficulty of damaging plant tissues (Padilla et al. 1996, Sigwart \& Carey 2014), are regularly considered in paleo-ecological studies (e.g. Prideaux et al. 2009, Kimura et al. 2013). However, they are often overlooked in the context of contemporary climate change, despite knowledge that the morphology and wear patterns on animal grazing structures can shift with environmental conditions and diet (e.g. snail radula: Padilla 1998; barnacle cirrus: Hoch 2011; oyster drill proboscis: Watanabe \& Young 2006). Elucidating the extent to which consumers are actively adapting their behavior and morphology, and plants are shifting in their vulnerability to grazing, are key elements to unraveling how and why consumer-plant interactions may change during episodes of climatic stress. Recent theory suggests that consumer-plant interactions may commonly strengthen with climate change where consumer behavioral shifts or weakening plant defenses cause the relative strength of top-down control to intensify as physical stress increases (Silliman \& $\mathrm{He}$ 2018).

To investigate these potential ecological responses to extreme climate events, we focused on a salt marsh consumer-plant interaction (Fig. 1). Salt marshes form in temperate, wave-protected bays and inlets around the world, where they provide valuable ecosystem services including nursery habitat provisioning, nutrient filtration, and carbon storage (Barbier et al. 2011, Costanza et al. 2014). They also offer an experimentally tractable ecosystem for studying consumer-plant interactions because most salt marshes are spatially dominated by a few species of monoculture-forming grasses and are regulated from the top down by a few, numerically dominant consumers (Pennings \& Bertness 2001). Along the southeast and Gulf of Mexico coasts of the USA, smooth cordgrass 

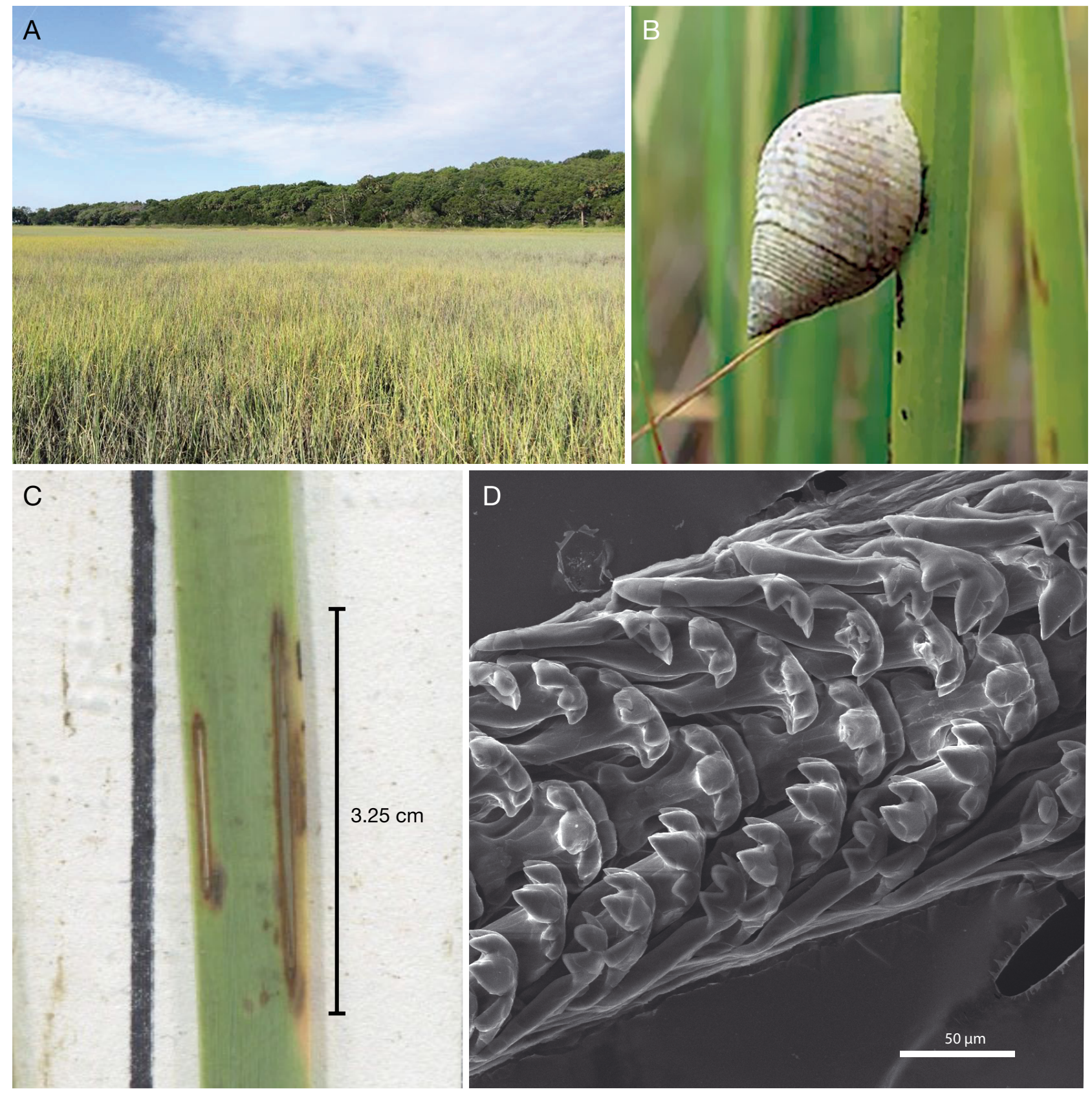

Fig. 1. (A) Salt marsh on Sapelo Island, Georgia (USA), structured by cordgrass Spartina alterniflora. (B) The dominant consumer in this system, the periwinkle snail Littoraria irrorata grazing on a cordgrass leaf. (C) Example of 2 snail-induced radulations. (D) Scanning electron microscope image of snail radula. Image credit: (C) Katheryne Cronk

Spartina alterniflora (hereafter 'cordgrass') is the foundation species that biogenically creates much of the salt marsh's physical structure and supports associated fauna (Odum \& Smalley 1959). The periwinkle marsh snail Littoraria irrorata (hereafter 'snail') is a dominant consumer in these marshes (Odum \& Smalley 1959). Snails both prune senesced cordgrass leaves, thereby stimulating nutrient cycling and cordgrass growth (Silliman \& Zieman 2001, Atkins et al. 2015), and use their radula, a narrow ribbon of chiton-based teeth, to form radulations, or wounds, in cordgrass leaves that can become infected with fungi, a protein-rich food source that the snails return to consume (Silliman \& Newell 2003). Although the snail-cordgrass-fungi interaction has been fairly well studied (e.g. Silliman et al. 2005, Hensel \& Silli- 
man 2013, Angelini et al. 2018), less is known about how snail behavior, grazing activities, and radula morphology respond to drought, which is a primary manifestation of climate change in the region (Wang et al. 2010). This knowledge is critical for predicting how structure and service provisioning of this ecosystem may change with predicted increases in regional drought severity and frequency (Chen et al. 2012).

The primary goals of this study were to test how drought affects snail spatial distribution, grazing patterns (i.e. radulation number, length, and level of fungal infection), and radula morphology and wear as well as the vulnerability of cordgrass to grazing and infection. We hypothesized that snails would migrate away from cordgrass leaves to stems to avoid hotter, less humid conditions in the plant canopy during drought; however, this shift would result in little change in the number, length, and fungal infection of snail radulations because drought-weakened plants are thought to be more susceptible to grazing than healthy plants (Silliman et al. 2005). We also hypothesized that the radula morphology (i.e. distance between teeth rows) would not change, but that radula would be longer and individual teeth on the radula would be sharper for snails exposed to drought relative to those exposed to control, nondrought conditions based on prior work suggesting that cordgrass becomes structurally weaker during drought (Silliman et al. 2005) and therefore less likely to induce frictional wear on the radula at both the scale of the whole radula and individual teeth. Collectively, this work advances our understanding of the mechanisms that moderate snail-cordgrass interactions during drought and broadens knowledge of the multi-faceted responses of consumers, plants, and their interactions to climate change.

\section{MATERIALS AND METHODS}

\subsection{Study system}

This study was conducted in the Sapelo Island National Estuarine Research Reserve in Georgia, USA ( $\left.31^{\circ} 24^{\prime} 29^{\prime \prime} \mathrm{N}, 81^{\circ} 17^{\prime} 23^{\prime \prime} \mathrm{W}\right)$. The experimental treatments were positioned within a higher-elevation salt marsh platform dominated by short-form cordgrass, which reaches a maximum canopy height of $50 \mathrm{~cm}$ during the growing season (Mendelssohn \& Morris 2000). At this site, snails (density $\sim 250$ ind. $\mathrm{m}^{-2}$ ), and other resident invertebrates such as ribbed mussels Geukensia demissa, fiddler crabs Uca pug- nax, and mud crabs (Panopeus obesus and Eurytium limosum), occur at moderate densities relative to those observed across the southeastern US Atlantic coast (Angelini et al. 2015). The experiment was initiated on 18 April 2014 and concluded on 13 August 2014, a period of time when the Palmer Drought Severity Index (PDSI) ranged from moderately wet $\left(\mathrm{PDSI}_{\text {April }}=2.33\right)$ to slightly dry $\left(\mathrm{PDSI}_{\text {August }}=-1.84\right)$ in the region (Georgia Region 9, NOAA National Climate Data Center; data available on https://www. ncdc.noaa.gov/temp-and-precip/drought/historicalpalmers/).

\subsection{Manipulative field experiment}

\subsubsection{Field experimental design}

Within this marsh platform, we marked 12 circular $0.02 \mathrm{~m}^{2}$ plots at $>1 \mathrm{~m}$ spacing, standardized for cordgrass canopy height $(25-30 \mathrm{~cm})$, stem density (1116 stems plot $^{-1}$ ), and invertebrate community composition. This relatively small plot size was chosen for logistical reasons (e.g. imposing removable climate chamber treatments at larger scales would be very challenging and introduce higher chances of tide water seepage/treatment failure); however, prior experiments of cordgrass-bivalve/crab-soil chemistry interactions conducted at a similar spatial scale (e.g. Sharp \& Angelini 2016, Derksen-Hooijberg et al. 2018) suggested it was large enough to investigate the effects of drought on the cordgrass-snail interaction. We randomly assigned either a climate chamber or control treatment to each plot $(\mathrm{n}=6$ replicates treatment ${ }^{-1}$ ), and all naturally occurring snails were removed from each plot (ambient density: $3.6 \pm 2.5$ snails plot $^{-1}$, mean $\pm \mathrm{SE}$ ). We then sunk a $16 \mathrm{~cm}$ diameter, $1 \mathrm{~cm}$ thick, $41 \mathrm{~cm}$ long PVC base tube and $9 \mathrm{~cm}$ tall connector socket into the marsh soil around each plot to a total depth of $50 \mathrm{~cm}$ to prevent water from flowing horizontally through the soil into climate chamber plots and to standardize the initial disturbance imposed via the PVC tube installation to the rhizosphere across all plots. A white plastic tube of $84 \mathrm{~cm}$ tall mesh (mesh size $=0.7 \mathrm{~cm}_{i}$ Vexar) that allowed water to flood the plots but prevented snails from escaping was then secured over each plot (Fig. 2A).

Climatic changes due to anthropogenic forces create warming periods in coastal ecosystems that are more likely to represent extreme conditions, for example, extreme droughts (Millennium Ecosystem Assessment 2005, Derksen-Hooijberg et al. 2019). 

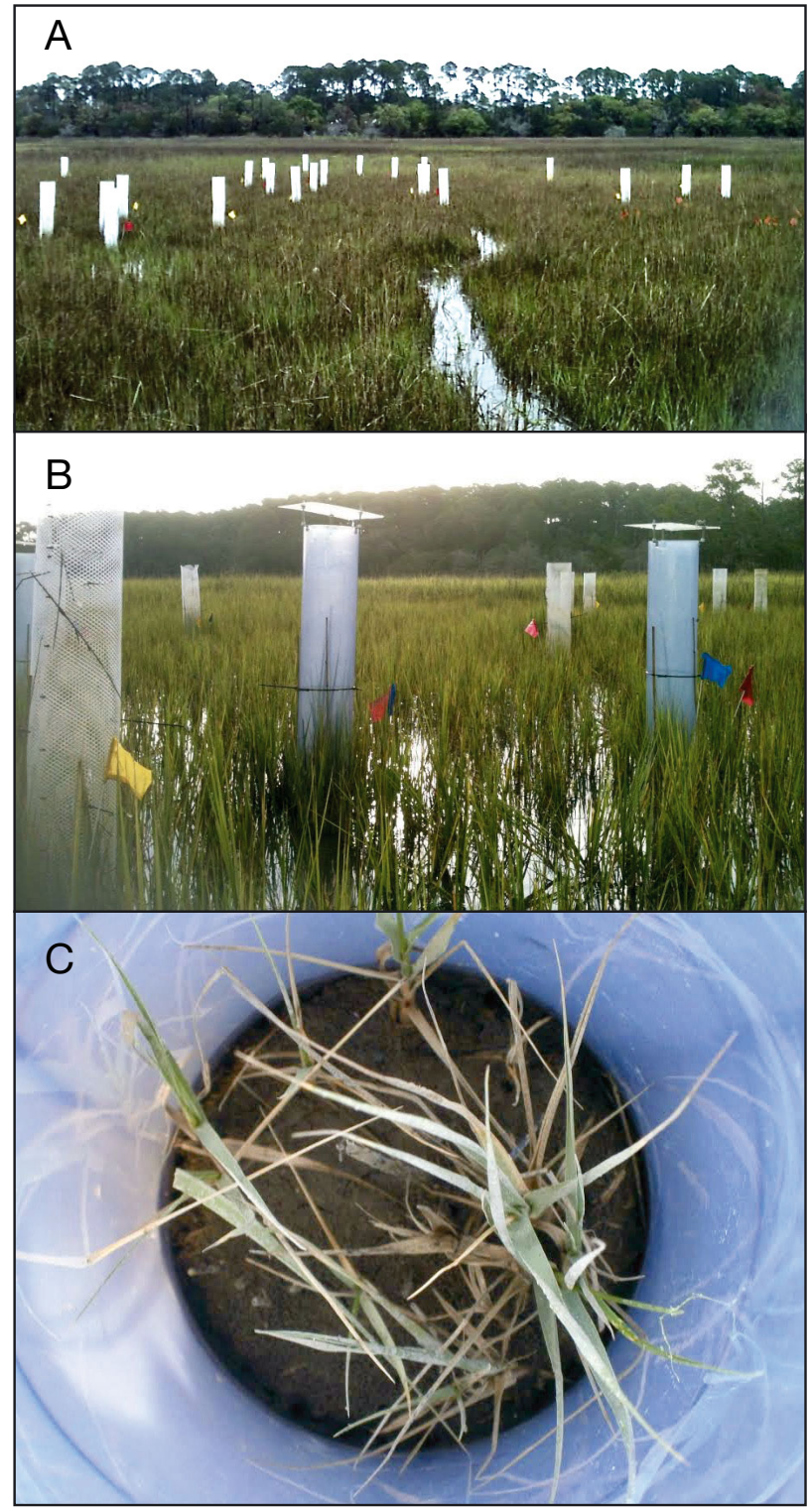

Fig. 2. Experimental field set-up of (A) control treatments with belowground PVC tubes and aboveground Vexar permeable mesh tubes; (B) climate treatments with above- and belowground PVC tubes and a sloping roof to dry the marsh by extending the duration of neap tide periods, exclude tidal water and rain, and warm the chambers; and (C) the interior of one of the tubes showing Spartina alterniflora above the marsh surface, which was inhabited by snails

These droughts are likely to increase in their frequency and severity with climate change intensification. Instances of repeated exposure to extreme drought are poorly studied, especially with regards to their impact on consumer-grazer interactions. To simulate hot, dry periods representative of summer drought in the region, we constructed removable climate chambers designed to dry the marsh by ex- tending the duration of neap tide periods when marsh platforms are not submerged by the tide, exclude rain, and warm the marsh surface and air. On 5 May, 1 June, 26 June, and 21 July 2014 for periods of $10,12,15$, and $20 \mathrm{~d}$, we carefully removed the mesh tube from each climate chamber plot and, in its place, secured an $84 \mathrm{~cm}$ tall clear PVC tube into the socket that extended $75 \mathrm{~cm}$ aboveground by covering the lower, exterior $9 \mathrm{~cm}$ of the clear tube with plumbers' putty (Hercules Sta Put) to create a watertight, but removable, seal (Fig. 2B,C). Over the 4 mo experiment, the clear PVC climate chamber tubes were repeatedly installed on the climate chamber plots to prevent tidewater from entering the plot for a few days before and after each naturally occurring neap tide, the period when the tidal amplitude is the lowest and the marsh platform does not naturally flood unless winds drive the tides onto the marsh (Sharp \& Angelini 2016). We extended the duration over which the climate chambers were deployed over the course of the experiment to reflect the increasingly severe and long-lasting periods of no rainfall that occur in the middle of the summer in the region (e.g. Derksen-Hooijberg et al. 2019). Because snails compulsively climb cordgrass stems when tidewaters flood the marsh, it must be noted that this design may have altered snail behavior not only via its effects on soil moisture and air temperatures but also by preventing cues carried in tide waters from interacting with snails in the climate chambers for a few days each month. Thus, by altering the tidal regime, we may have affected not only the microclimate, but also factors influencing snail behavior.

To exclude rain but enable air exchange, we secured with bolts a clear acrylic (OPTIX; size $254 \times 203$ $\times 0.20 \mathrm{~mm}$ ) roof $12 \mathrm{~cm}$ above each climate chamber tube (Fig. 2B). After each climate chamber-induced hot and dry period, we once again replaced each PVC climate chamber tube with a mesh tube that allowed water to flood the plots but prevented snails from escaping. All mesh tubes including those secured to control plots were manually scrubbed clean between each climate chamber deployment to reduce fouling and potential shading and to standardize disturbance effects across treatments. As we observed tide water flooding the surface into 2 of the 6 climate chamber plots during neap tides, indicating that they were failing to exclude the tide and maintain dry conditions, we excluded these plots from all analyses. We suspect that desiccation-induced soil shrinkage allowed subsurface water to seep into these plots.

On 25 April, 1 wk after installing the belowground PVC tubes, we added 5 snails, between 10.7 and 
$14.8 \mathrm{~mm}$ in spire height, to each plot to impose nearambient densities of the most common marsh consumer (Fig. 2C). Snails that disappeared or died (a total of 5 individuals over the entire experiment) were replaced immediately from an extra climate chamber or control treatment plot that we kept stocked with snails for the duration of the experiment.

\subsubsection{Climate variables}

To assess whether the experimental treatments indeed created drought-like and non-drought conditions, we used micro-rhizons (Van Walt) to sample porewater from the top $5 \mathrm{~cm}$ of soil, where the cordgrass roots are concentrated. Micro-rhizons were placed in the center of each plot and sampled $2 \mathrm{~d}$ after the conclusion of each drought (neap tide) period, when plots were re-wet and extraction of porewater from all plots was possible. We measured the salinity of each sample using a multimeter (340i; WTW) connected to a conductivity sensor (TetraCon 325; WTW). For each date, we evaluated the effect size and significance of treatment on salinity using a $t$-test assuming unequal variances.

To quantify the effects of the climate and control chambers on temperature and humidity, we installed iButtons (Embedded Data Systems), programmed to record data every $5 \mathrm{~min}$, for $6 \mathrm{~h}$ deployments on the marsh surface in 4 replicates of each treatment (due to a limited number of data loggers) and in 4 unmanipulated marsh locations within the experimental field site for $1 \mathrm{~d}$ in June and $1 \mathrm{~d}$ in July. We calculated the average temperature and humidity recorded by each logger on each day and used $t$-tests assuming unequal variances to assess the effect size and significance of plot type (climate, control, and unmanipulated marsh) on temperature and humidity recorded on each date.

\subsubsection{Snail behavioral responses}

In the third drought-simulation period (i.e. when the climate chamber tubes were re-installed) and a few days thereafter from 26 June to 18 July, we surveyed snails periodically at 11 time points to assess whether they modified their spatial distribution in response to hot, dry conditions in the climate chambers relative to controls. Each day during low tide, we counted the number of snails present on the tube (clear PVC or Vexar), live stems $(<5 \mathrm{~cm}$ from the surface), live leaves, dead stems, or the ground. Because snails were overwhelmingly observed on live stems or leaves (123 of 132 total observations), we used a generalized linear model with a binomial error distribution that included treatment and time as fixed factors to assess the effects of climate chamber treatment on snail presence on stems or leaves as the chambers were installed and removed over time.

On 13 August, the experiment was terminated and all aboveground cordgrass stems were harvested from each plot. In the lab, all stems were then carefully separated into individual leaves, mounted onto a color scanner and scanned. In ImageJ (Schneider et al. 2012), we collected data on leaf length as well as the length of each radulation. Radulations can be differentiated from other damage based on their characteristic orientation (i.e. radulations run parallel to the leaf venation) and slightly roughened wound margins created by the snail's rasping radula (Silliman \& Zieman 2001, Silliman \& Newell 2003). From these measures, we calculated (per plot) the total length of leaves (the sum of the lengths of all leaves), total radulation length (the sum of all radulations), the number of radulations per stem, the average radulation length per stem, and the percent of stem length grazed (total radulation length divided by the total leaf length, and multiplied by 100).

For each radulation, a single researcher also scored its fungal infection on a scale from $0-5$, with 0 indicating no visible senesced, decomposing tissue bordering the radulation wound and 5 indicating a severe fungal infection in which senesced, decomposing tissue lined all wound margins and extended at least $1 \mathrm{~mm}$ into the adjacent plant tissue. Of note, this metric evaluates the extent of fungal infection existing around the radulation margin, and does not identify whether snails have removed some/all of the fungal infection which may have occurred around the radulation via their grazing activities; thus, these measurements may underestimate the rate of fungal infection. Due to the corruption of scanned image files for 2 control plots and 1 climate chamber plot in addition to the treatment failure of 2 climate chamber plots (see Section 2.2.1; 2 plots failed to exclude the tide and did not maintain the necessary dry conditions), stem length, radulation, and fungal infection data were available and analyzed for 4 replicate control and 3 replicate climate chamber plots.

We used $t$-tests to examine the effect of the climate treatment on total stem length and on each radulation metric, and the mean fungal infection score per plot. The percent of stems grazed was arcsine square root transformed to meet assumptions of normality. Because we found that radulation lengths were 
shorter in climate than control chamber treatments and hypothesized that radulation wounds of the same length may be relatively more infected with fungus in the climate than control treatments, we then used an ANOVA that controlled for climate treatment and radulation length with fungal score as the response variable to evaluate this hypothesis.

\subsubsection{Snail morphological responses}

We first used digital calipers to measure spire height from the shell base to tip of each snail collected from the experiment. We then removed the shell and dissolved the muscle and visceral tissue in household bleach to extract the radula (Scheltema et al. 2003). Using fine tweezers, we rinsed each radula with water and laid it flat on a clean surface to measure its length using digital calipers. Each taenioglossate radula, meaning the radula contains 7 teeth per transverse row, was then mounted onto an aluminum stub with carbon tape. These stubs were then carbon coated before being imaged with a Tescan Vega II XMU scanning electron microscope (SEM) at 500$800 \times$ magnification. We then identified SEM images taken near the mid-point of each radula in which the teeth rows were positioned parallel to the plane of view and used the line function in ImageJ to measure the distance between adjacent teeth rows from the tip of the central rachidian tooth to the tip of the central rachidian tooth on the next transverse row. We repeated this measurement 4 times per radula. By dividing each measured radula length by average distance between teeth rows measured for that radula, we estimated the number of teeth rows per radula. We then outlined the outer cusp of the central rachidian tooth and used ImageJ's angle function to assess tooth sharpness (i.e. smaller angles indicate sharper teeth) and repeated this for 4 rachidian teeth per radula. We identified SEM images also taken near the mid-point of each radula where the marginal teeth were positioned perpendicular to the plane of view and, in Image J, measured the sharpness of the outermost marginal teeth by outlining the cusp of 4 marginal teeth, also with ImageJ's angle function. We processed a subset of the snails $(n=16$ from controls, 19 from climate chamber treatments; snails were selected randomly from the total of 30 and 20 snails collected from the experimental treatments, respectively) due to the limited availability of the SEM used for these analyses.

We then used $t$-tests to assess the effect size and significance $(p<0.05)$ of climate chamber treatment on each snail radula response variable (average length of radula, ratio of radula length to spire height, average number of teeth rows per radula, and average central and marginal tooth angle). All analyses were conducted using the statistical computing software R version 3.2.3 (R Core Team 2015).

\section{RESULTS}

\subsection{Effects of climate chambers}

The presence of climate chambers caused porewater salinity and temperature to increase, and relative humidity to decrease, relative to controls on both June and July monitoring dates (pairwise $t$-tests, Treatment: $\mathrm{p}<0.0001$ for all variables on both dates). Specifically, relative to controls, climate chambers induced a $70 \%$ increase in porewater salinity from $29.2 \pm 0.5$ to $50.4 \pm 4.1$, mean $\pm \mathrm{SE}$, and increased temperatures by $5.8^{\circ} \mathrm{C}$ (from $34.2 \pm 0.13$ to $40.0 \pm$ $0.18^{\circ} \mathrm{C}$ ) and $6.4^{\circ} \mathrm{C}$ (from $40.0 \pm 0.11$ to $43.3 \pm 0.17^{\circ} \mathrm{C}$, $\mathrm{p}<0.0001$ ) on the June and July monitoring dates, respectively. Concurrently, temperatures in unmanipulated marsh plots were slightly warmer than control plots (i.e. those surrounded by mesh) and cooler than clear PVC-enclosed climate chamber plots in June $\left(38.0 \pm 0.24^{\circ} \mathrm{C}\right)$, but were cooler than both treatments in July $\left(38.6 \pm 0.12^{\circ} \mathrm{C}\right)$. Relative humidity was significantly higher in control (61.7 \pm 0.34 and $58.4 \pm 0.50 \%, \mathrm{p}<0.0001)$ than climate chamber treatments $(52.4 \pm 0.44$ and $50.4 \pm 0.47 \%)$ in June and July, respectively. In unmanipulated marsh plots, relative humidity was similar to the control plots in June $(62.0 \pm 0.5 \%, \mathrm{p}=0.28)$ but significantly higher than controls in July $(64.0 \pm 0.54 \%, p<$ 0.0001).

\subsection{Climatic effects on snail behavior}

During periods when the climate chambers were deployed, a larger proportion of snails were attached to cordgrass stems, rather than on the leaves or ground, in the climate chambers than controls (Time $\times$ Treatment: $Z=-1.9, \mathrm{p}<0.001$; Fig. 3). Once the climate chambers were replaced with mesh, however, snail distributions became similar across treatments (Fig. 3). Coincident with these temporary shifts away from cordgrass leaves to bases when conditions within the tubes were hot and dry, snails increased the number but decreased the length of radulations they inflicted on cordgrass stems 


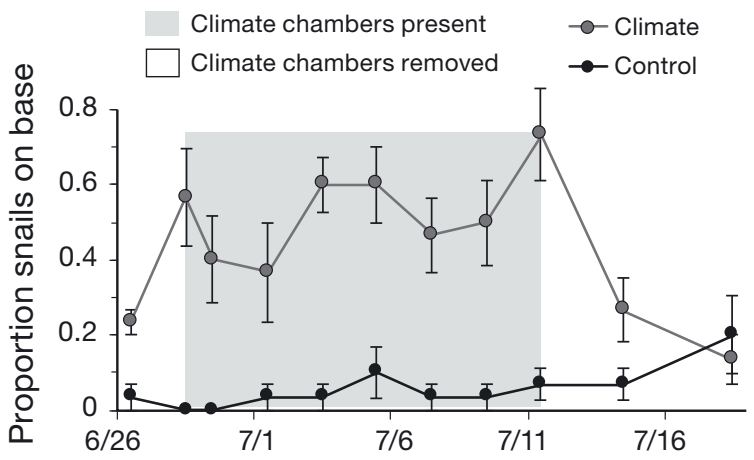

Fig. 3. Shifts in snail distribution from cordgrass stem bases over time in climate chamber (grey lines) and control (black lines) treatments. The period when the climate chambers were secured over plots is indicated in grey while the period where the climate chambers were removed and all plots experienced equivalent tidal inundation is indicated in white. Data at each time point are means \pm SE for each treatment

(Fig. 4A,B). Specifically, the number of radulations per stem was 1.6 times higher $\left(t_{5}=2.01, \mathrm{p}=0.04\right.$, Fig. 4A), but individual radulations were only $28 \%$ as long in climate chambers relative to controls $\left(t_{5}=\right.$ $2.04, \mathrm{p}=0.001$; Fig. 4B). These shifts in radulation number and length resulted in the total length of radulations per plot being only about half as long $(63.6 \pm 3.0$ vs. $113.6 \pm 12.0 \mathrm{~cm}$, mean $\pm \mathrm{SE})$, and the percent of cordgrass leaf length grazed being only about $1 / 3$ as high $(2.4 \pm 0.4$ vs. $7.8 \pm 1.9 \%$ of leaf length grazed) in climate compared to control plots, respectively, although these differences were not statistically significant likely due to our limited replication of each treatment $\left(t_{5} \leq 4.3, \mathrm{p}=0.21\right.$, $p=0.12$; Fig. $4 \mathrm{C}, \mathrm{D})$. By scoring the severity of fungal infection of radulations, we also found that fungal infection levels were higher on average in controls than in climate chambers $\left(t_{5}=1.98, \mathrm{p}<0.001\right.$; Fig. 4E). However, when standardized for radulation length, fungal infection scores were significantly higher for radulations observed in the climate chambers compared to controls (Treatment $\times$ Radulation Length: $\left.F_{1,55}=32.6, \mathrm{p}<0.001\right)$. Total cordgrass leaf length was similar in climate and control treatments $(p=0.22)$.

\subsection{Climatic effects on snail morphology}

Although the distance between teeth rows was similar between climate chambers and controls (an average distance of $78.31 \mu \mathrm{m}$ in the climate treatments versus $74.33 \mu \mathrm{m}$ in the control, $\mathrm{p}=0.14$ ), all other measures of radula morphology differed among treatments. At the whole-radula scale, the total length of radulae extracted from snails exposed to hotter, drier conditions in the climate chamber plots was $33 \%$ longer $\left(t_{1,33}=20.17, p<0.001\right.$; Fig. $\left.5 \mathrm{~A}\right)$, and both the ratio of radula length to shell spire height $\left(t_{1,33}=\right.$ 22.66, $\mathrm{p}<0.001$; Fig. 5B) and the total number of teeth rows per radula $\left(t_{1,33}=12.97, p=0.001\right.$; Fig. 5 C) were about $30 \%$ greater in climate chambers than controls. The tooth angle of rachidian teeth was $13.71^{\circ}$ wider on average, indicating these centrally positioned teeth were blunter, in climate chambers than in control plots $\left(t_{1,33}=7.13, \mathrm{p}<0.001\right.$; Fig. $\left.5 \mathrm{G}, \mathrm{H}\right)$. However, lateral teeth exhibited the opposite pattern, whereby the angle of lateral teeth was $22.13^{\circ}$ narrower on average, indicating sharper lateral teeth, on radulae extracted from snails exposed to climate chambers relative to control treatments $\left(t_{1,33}=\right.$ $3.61, \mathrm{p}=0.07$; Fig. 5E,F).
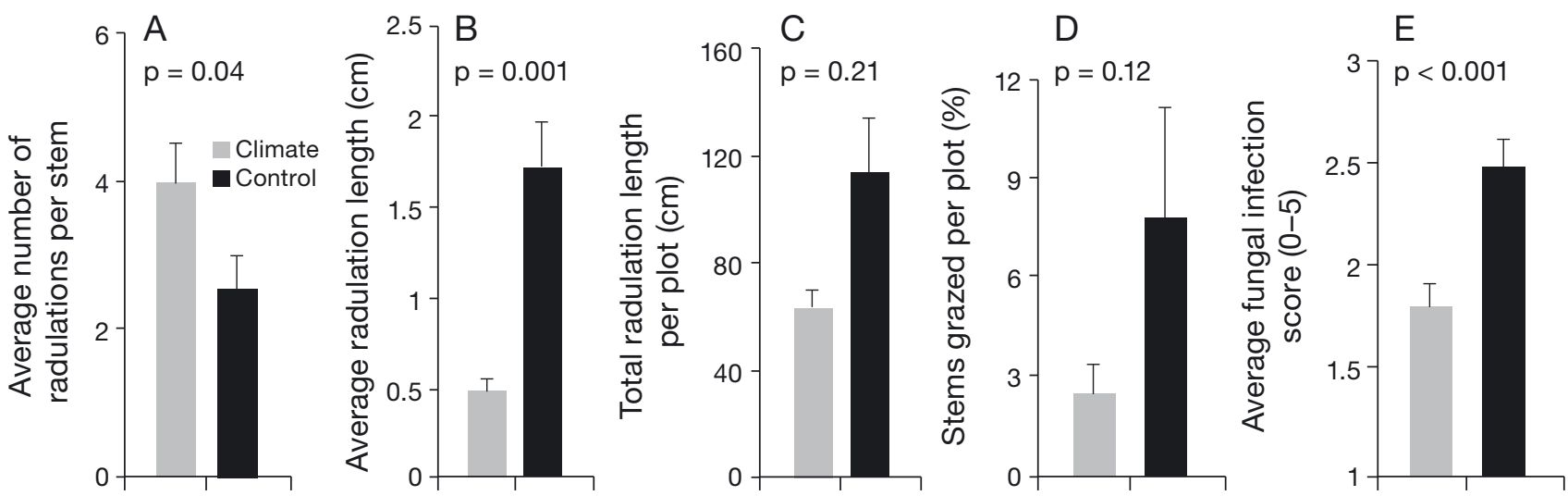

Fig. 4. Effects of climate chambers on snail grazing damage after 4 mo. (A) Average number of radulation scars stem ${ }^{-1}$ plot $^{-1}$. (B) Average length of radulations plot $^{-1}$. (C) Total length of radulations plot ${ }^{-1}$. (D) Percent of cordgrass stems grazed. (E) Average fungal infection score stem ${ }^{-1}$ plot $^{-1}$. Data are the means \pm SE for each treatment; $p$-values indicate the significance of climate chamber treatment on each response metric as assessed by Student's $t$-tests 

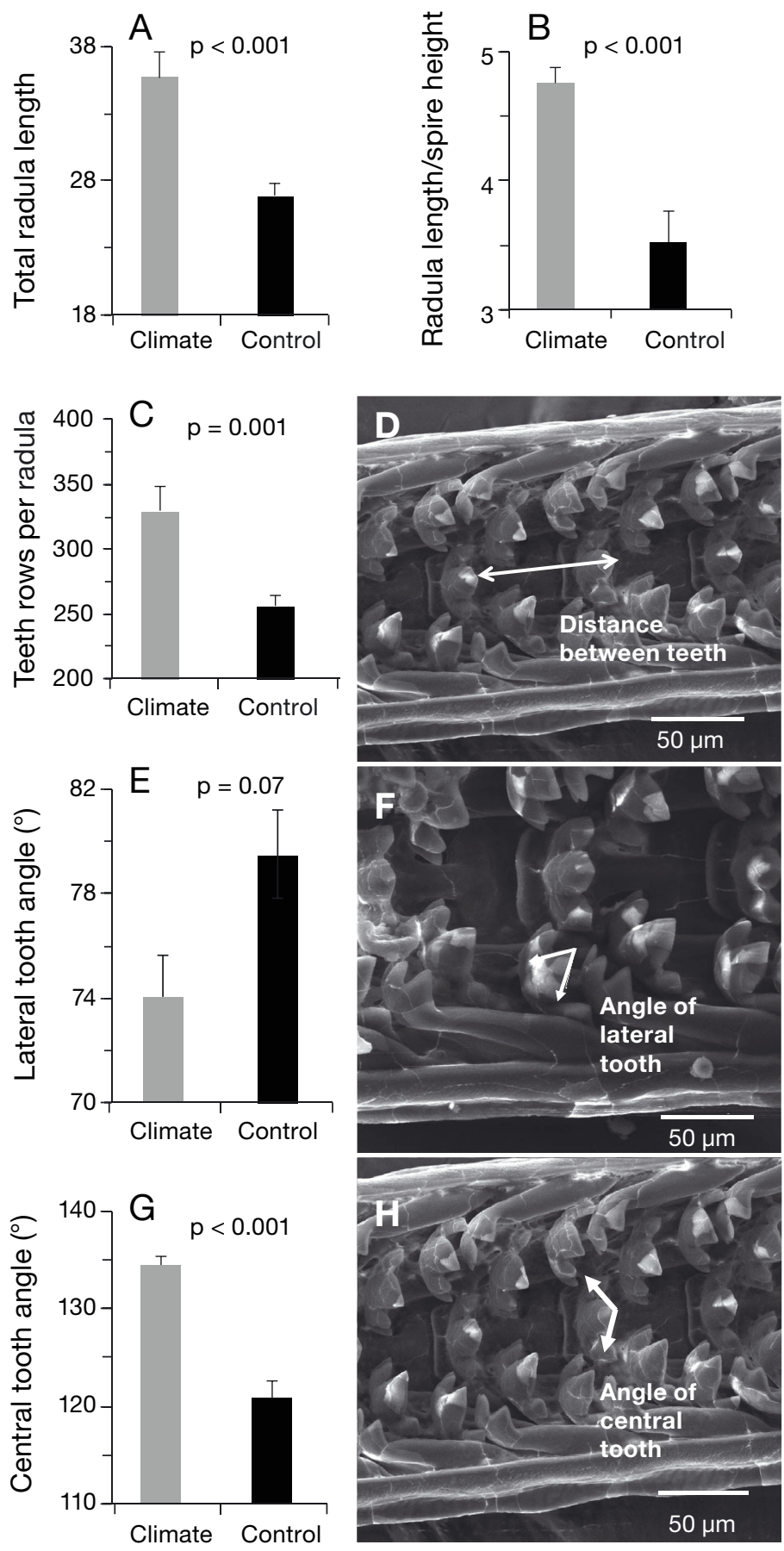

Fig. 5. Changes in snail radula morphology in response to climate chamber treatments $(n=16$ snails for climate treatments and 19 for control treatments). (A) Average total radula length. (B) Ratio of radula length to spire height. (C) Average number of teeth rows per radula. (D) Scanning electron microscope (SEM) image showing distance measurement on center teeth from tip to tip. (E) Lateral tooth angle (in degrees). (F) SEM image showing tooth sharpness measurement on side teeth using the angle function in ImageJ. (G) Central tooth angle (in degrees). (H) SEM image showing tooth sharpness measurement on central teeth using the angle function in ImageJ. Data are means \pm SE for each treatment; $\mathrm{p}$-values indicate significance as assessed by $t$-tests

\section{DISCUSSION}

\subsection{Overall effects}

This study provides the first experimental evidence that stressful climate conditions can induce significant changes in snail radula morphology and suggests that drought-provoked shifts in snail spatial distributions and grazing activities may weaken top-down consumer effects on foundational marsh cordgrass. We discovered that snails congregate close to the marsh surface on cordgrass stems during periods of climatic stress. This is presumably to avoid direct contact with salt, a desiccant, both excreted by cordgrass leaves and crystalized on the marsh surface (Windham et al. 2001), and to seek refuge where humidity levels likely remain higher due to evapotranspiration of soil moisture and lower temperatures due to shading by the cordgrass canopy. Once stressful conditions subsided, however, snails generally returned to the leaves. Importantly, these behavioral changes appeared to reduce the cumulative damage snails inflicted on cordgrass leaves, and the average severity of fungal infection of radulations. These experimental results indicate that droughts can provoke periods when snail-cordgrass-fungal interactions relax as snails wait out these stressful events and that shifts in interaction strength can correspond to shifts in consumer morphology.

\subsection{Behavioral response}

During episodes of drought, heat, and no tidal exposure imposed by the climate chambers, snails generally shifted from cordgrass leaves to stem bases, but promptly returned to leaves when climate chambers were removed, physical stress levels abated, and natural tidal flooding regimes were re-established (Fig. 3). The affinity of snails for stems during high-stress periods suggests that this lower canopy level is less stressful than either the leaves or marsh surface and thus provides a critical refuge. This behavior is similar to that of mangrove crabs that take shelter among mangrove pneumatophores during hot, dry summer days to avoid desiccation and concentrate their grazing on detritus lodged among these aerial roots (Wilson 1989). As previously proposed in ecological theory (Silliman \& He 2018), this type of behavior may thus reflect a more general re- 
sponse of consumers to damp down their grazing activities during highly physically stressful conditions.

The observed response of snails reducing the extent of their grazing on cordgrass leaves during drought diverges from that documented for the same southeastern US salt marsh system (Silliman et al. 2005). In this prior study, Silliman et al. (2005) documented the presence of high-density snail fronts along cordgrass die-off patch borders. They implemented field experiments in which they both manipulated snail presence along die-off borders, removed snails, and added salt to explore interactions between snail grazing and drought-associated soil salinity stress. Their results showed that snail grazing fronts can dramatically expand die-off patches along the US Gulf and south Atlantic coasts, and that snails suppress cordgrass growth more when the grass was simultaneously stressed by high soil salinity (Silliman et al. 2005).

We suspect that the different snail densities, spatial scales of the experimental treatments, and types of drought manipulations (i.e. salt addition to soils that physiologically stressed plants vs. climate chambers that affected soil and air properties, stressed both snails and plants, and severed plant roots/rhizomes upon installation) investigated in the study by Silliman et al. (2005) versus ours were key factors determining the magnitude and direction of snail-cordgrass interaction responses to drought. At moderate densities (this study), snails may not have to compete for space on stem bases and thus persist in these high-quality refuges for the duration of the stress events. At high snail densities, however, limited space on stem bases may force snails to position themselves either on the surface, which can become extremely hot and dry $\left(46^{\circ} \mathrm{C}\right.$; C. Angelini unpubl. data) or, more likely, on cordgrass leaves where snails gradually shred the drought-stressed canopy apart (Atkins et al. 2015). After locally eliminating the cordgrass stems under this high-density scenario, snails are forced to migrate to the borders of the dieoffs where refuge-providing cordgrass stems remain, thereby forming even higher-density grazing fronts. Importantly, this phenomenon can only arise at spatial scales large enough to permit snail migration and front-formation.

Thus, our study and the study by Silliman et al. (2005) complement one another in suggesting that, while drought may weaken snail top-down control of cordgrass where consumer densities are low to moderate, it may strengthen their effects where snail densities are high. Importantly, these 2 studies differ in their manipulation of stresses, where our study employed a 'pulsed' disturbance, or relatively short, but repeated periods of elevated stress, and the study by Silliman et al. (2005) considered a 'press' disturbance, in which drought conditions persisted over a 14 mo period. It may be worthwhile to investigate in future studies whether cordgrass invests in chemical defenses, such as defensive symbionts (i.e. endosymbiotic fungi existing in mutualism within infected grasses) or biochemical compounds (i.e. plant phenols, a common defensive mechanism against herbivores, secondary metabolites, and increased concentrations of siliceous compounds or cyanide with plant tissues) (Briske 1996, War et al. 2012). Inducible plant defenses against the pressures of higher grazing may also include physical defenses, which should also be investigated in cordgrass, such as the presence of a protective structural defenses like increased cell wall thickness or lignification in order to ward off consumer effects at higher snail densities (War et al. 2012). Further experiments that pinpoint where thresholds in snail density occur in drought-stressed and non-stressed marshes are needed to evaluate where foundational cordgrass, as well as its associated community and functions, are likely to collapse under future climate scenarios.

The observed shifts in snail spatial distribution away from leaves corresponded to a net reduction in grazing pressure on cordgrass and a lesser average severity of fungal infection of radulations in response to climate treatments in our study (Fig. 4). In particular, although individual radulations were more numerous, they were shorter and damaged a smaller proportion of the total cordgrass leaf area available in climate than control treatments. These results indicate that snail grazing behaviors change when they became climate-stressed; instead of rasping at the margins of wounds for long periods of time or returning to expand the size of existing radulations, snails initiate more, new radulations with increased physical stress. This behavioral shift may indicate that the climate treatments were so physically stressful that the snails suspended their rasping activities after short periods of time due to fatigue, and/or perhaps they can acquire more water from plant tissues by creating fresh wounds as opposed to grazing existing wounds. Alternatively, snails may have opportunistically adapted to create smaller scars because fungi appeared to readily infect the margins of these small wounds when the plants were also stressed (Fig. 4E). Contrasting with this explanation, fungi simply may not have been able to grow as effectively in climate chambers due to the induced climatic effects of low- 
ered humidity and increased temperatures, resulting in automatically lowered fungal damage and radulation scarring. Although both temperature and humidity appear not to be limiting factors in the growth of common fungi species, a lack of persistent moisture condensation on the cordgrass leaves could have stunted the growth of the fungi and thus affected the availability of fungi as a food source for snails (Pasanen et al. 1991). Resolving which of these potential pathways govern snail behavior is important because in the first scenario, snails may consume less overall and therefore experience reductions in growth and fitness, while in the second scenario, drought may have little effect on a snail's fitness and enable snails to have similar or even stronger effects on cordgrass over time.

To further elucidate whether drought indeed affects snail fitness, we recommend that follow-up studies investigate additional fitness and performance metrics such as the time snails spend grazing, snail condition (e.g. shell mass:visceral mass), snail growth rate, and reproductive output. Additionally, further studies should look at the effects of climatic variables on the growth of fungi to determine how much biomass is available for grazers to consume. We re-emphasize our limited sample size in these plots, due to flooding in 2 of the control plots and corruption of scanned images in both the climate and control plots. We recognize that this constraint in our experimental design in turn limits the statistical power of our experiment, and therefore encourage follow-up studies to integrate a higher amount of replication in their investigations.

\subsection{Morphological response}

In our study, we also discovered that radula morphology shifts at both the entire radula ribbon (i.e. total length and ratio of length to spire height) and individual tooth (i.e. lateral and central tooth sharpness) scales when snails are exposed to altered climatic conditions. The enhanced radula length and heightened ratio of radula length to spire height indicate that, regardless of snail size, the radulae were relatively longer in the climate chamber treatments. Furthermore, both the increased sharpness of lateral teeth and reduced sharpness of the central rachidian teeth in the climate chamber compared to control treatments indicate that the radula are either morphologically adapting the shape of individual teeth and/or experiencing differences in wear in response to periods of stress. In closely related snail species
(Padilla 2001), the radula ribbon is continuously produced and replaced fully about every $25 \mathrm{~d}$, and the oldest, anterior teeth are the ones that make contact with plants, rocks, and other surfaces as snails graze (Grünbaum \& Padilla 2014). In the climate-stressed snails, the response time from the start of the experiment to its conclusion was certainly long enough to facilitate the full replacement of teeth, and thus the snail's adaptive morphology.

There are several potentially complementary explanations for the reduced wear on the radula and shifts in tooth morphology in the climate chambers. First, the snails appeared to rasp their radula on the cordgrass leaves less, as we measured considerably less grazing damage in the climate treatments. This finding is consistent with a prior study showing that snail radula length increases with a net decrease in foraging time (Ito et al. 2002). Second, cordgrass leaves may have been relatively 'softer' in the climate chambers than control treatments as a result of the plants being drought-stressed and weakened, which in turn reduced their investment in sclerophylly, or as a result of fungi degrading plant polysaccharides associated with structure. Tissue toughness is widely regarded across invertebrate and vertebrate consumers to be one of the most important physical mechanisms that influences grazing of plants and the reduction of their accessibility and palatability, and thus the yellowing, wilting, and decaying associated with drought-stress cordgrass certainly may have altered snails' grazing preferences (Briske 1996). As proposed by Silliman \& Zieman (2001), it may thus have been relatively easier for the snails to rasp with their lateral teeth. Additionally, the central teeth may have become broader and blunter as the snails became increasingly dependent on scooping up fungus from wound margins in the climate treatments. Prior research has demonstrated similar inducible plasticity of the radula of Lacuna spp., benthic snails that shift from producing sharp central rachidian teeth when grazing on fleshy algae to blunt teeth when grazing on diatoms (Padilla 1998). Together with our results, this research and other studies showing similar responses (Jørgensen 2001, Grünbaum \& Padilla 2014, Clewing et al. 2015) indicate that changes in radula morphology may be a common response of gastropod consumers to shifting environmental conditions. Regardless of the underlying reason, the observed reduction of radula wear and inducible shifts in tooth morphology suggest that snails needed to invest fewer resources in maintaining their grazing apparatus in the climate chamber relative to control treatments. We suggest that this 
may be an important mechanism for conserving energy during stressful periods when grazing and, hence, food uptake rates are reduced (Reid \& Mak 1999).

\subsection{Conclusions}

Combined, our results suggest that snails, which are dominant consumers in southeastern US salt marshes, can dynamically respond to episodes of climate stress via multiple behavioral and morphological pathways that together reduce their net grazing impacts on the foundational grass. More broadly, these findings highlight that the importance of top-down effects of consumers on primary producers are sensitive to climatic stressors, leading to potential shifts in the strength and even direction of consumer-plant interactions. Further investigations that quantify reciprocal and multi-faceted responses of plants and consumers are needed to elucidate when, where, and why plant-consumer interactions are likely to intensify or relax with climate change across diverse ecosystems.

Acknowledgements. We thank the Georgia Coastal Ecosystems LTER and Sapelo Island National Estuarine Research Reserve for access to field sites and technical assistance. Funding supporting this work was provided to C.A. by the National Science Foundation Division of Environmental Biology (award number: 1546638) and Chemical, Bioengineering, Environmental, and Transport Systems (award number: 1652628).

\section{LITERATURE CITED}

Agrawal AA (2001) Phenotypic plasticity in the interactions and evolution of species. Science 294:321-326

Angelini C, van der Heide T, Griffin JN, Morton JP and others (2015) Foundation species' overlap enhances biodiversity and multifunctionality from the patch to landscape scale in southeastern United States salt marshes. Proc R Soc B 282:20150421

Angelini C, Van Montfrans SG, Hensel MJS, He Q, Silliman BR (2018) The importance of an underestimated grazer under climate change: how crab density, consumer competition, and physical stress affect salt marsh resilience. Oecologia 187:205-217

* Atkins RL, Griffin JN, Angelini C, O'Connor MI, Silliman BR (2015) Consumer-plant interaction strength: importance of body size, density and metabolic biomass. Oikos 124: 1274-1281

* Barbier E, Hacker S, Kennedy C, Stier A, Silliman B (2011) The value of estuarine and coastal ecosystem services. Ecol Monogr 81:169-193

Berlow E, Neutel AM, Cohen JE, De Ruiter PC and others (2004) Interaction strengths in food webs: issues and opportunities. J Anim Ecol 73:585-598
Briske DD (1996) Strategies of plant survival in grazed systems: a functional interpretation. In: Hodgson J, Illius AW (eds) The ecology and management of grazed systems. CAB International, Wallingford, p 37-67

* Bruno JF, Selig ER, Casey KS, Page CA and others (2007) Thermal stress and coral cover as drivers of coral disease outbreaks. PLOS Biol 5:e124

Chen G, Tian H, Zhang C, Liu M and others (2012) Drought in the Southern United States over the 20th century: variability and its impacts on terrestrial ecosystem productivity and carbon storage. Clim Change 114:379-397

* Clewing C, Riedel F, Wilke T, Albrecht C (2015) Ecophenotypic plasticity leads to extraordinary gastropod shells found on the 'Roof of the World'. Ecol Evol 5:2966-2979

* Costanza R, de Groot R, Sutton P, van der Ploeg S and others (2014) Changes in the global value of ecosystem services. Glob Environ Change 26:152-158

*Daleo P, Silliman B, Alberti J, Escapa M, Canepuccia A, Peña N, Iribarne O (2009) Grazer facilitation of fungal infection and the control of plant growth in south-western Atlantic salt marshes. J Ecol 97:781-787

* Derksen-Hooijberg M, Angelini C, Lamers LPM, Borst A and others (2018) Mutualistic interactions amplify saltmarsh restoration success. J Appl Ecol 55:405-414

* Derksen-Hooijberg M, Angelini C, Hoogveld JRH, Lamers LPM and others (2019) Repetitive desiccation events weaken a salt marsh mutualism. J Ecol 00:1-12

* García-Guzmán G, Dirzo R (2001) Patterns of leaf-pathogen infection in the understory of a Mexican rain forest: incidence, spatiotemporal variation, and mechanisms of infection. Am J Bot 88:634-645

KGilbert B, Tunney TD, McCann KS, DeLong JP and others (2014) A bioenergetic framework for the temperature dependence of trophic interactions. Ecol Lett 17: 902-914

Graca M, Newell S, Kneib R (2000) Grazing rates of organic matter and living fungal biomass of decaying Spartina alterniflora by three species of salt-marsh invertebrates. Mar Biol 136:281-289

*Günbaum D, Padilla DK (2014) An integrated modeling approach to assessing linkages between environment, organism, and phenotypic plasticity. Integr Comp Biol 54:323-335

* He Q, Silliman BR (2015) Biogeographic consequences of nutrient enrichment for plant-herbivore interactions in coastal wetlands. Ecol Lett 18:462-471

* Hensel MJS, Silliman BR (2013) Consumer diversity across kingdoms supports multiple functions in a coastal ecosystem. Proc Natl Acad Sci USA 110:20621-20626

* Hoch JM (2011) Effects of crowding and wave exposure on cirrus morphology of the acorn barnacle, Semibalanus balanoides. J Crustac Biol 31:401-405

* Ito A, Ilano AS, Goshima S, Nakao S (2002) Seasonal and tidal-height variations in body weight and radular length in Nodilittorina radiata (Eydoux \& Souleyet, 1852). J Molluscan Stud 68:197-203

Jørgensen A (2001) Variation in radular teeth and acuspid side of the radula in Lacuna pallidula, L. parva and $L$. vincta (Gastropoda: Littorinidae) from the Isle of Wight, United Kingdom. Helgol Mar Res 55:95-100

Kimura Y, Jacobs LL, Cerling TE, Uno KT, Ferguson KM, Flynn LJ, Patnaik R (2013) Fossil mice and rats show isotopic evidence of niche partitioning and change in dental ecomorphology related to dietary shift in late Miocene of Pakistan. PLOS ONE 8:e69308 
Mendelssohn IA, Morris JT (2000) Eco-physiological controls on the productivity of Spartina alterniflora Loisel. In: Weinstein MP, Kreeger DA (eds) Concepts and controversies in tidal marsh ecology. Springer, Dordrecht, p 59-80

Menge B, Sutherland J (1987) Community regulation: variation in disturbance, competition, and predation in relation to environmental stress and recruitment. Am Nat 130:730-757

Meserve PL, Kelt DA, Milstead WB, Gutiérrez JR (2003) Thirteen years of shifting top-down and bottom-up control. Bioscience 53:633-646

Millennium Ecosystem Assessment (2005) Ecosystems and human well-being: synthesis. Island Press, Washington DC

Muschick M, Barluenga M, Salzburger W, Meyer A (2011) Adaptive phenotypic plasticity in the Midas cichlid fish pharyngeal jaw and its relevance in adaptive radiation. BMC Evol Biol 11:116

Newell SY, Barlocher F (1993) Removal of fungal and total organic matter from decaying cordgrass leaves by shredder snails. J Exp Mar Biol Ecol 171:39-49

* O'Connor MI (2009) Warming strengthens an herbivoreplant interaction. Ecology 90:388-398

Odum EP, Smalley AE (1959) Comparison of population energy flow of a herbivorous and a deposit-feeding invertebrate in a salt marsh ecosystem. Proc Natl Acad Sci USA 45:617-622

Padilla D (1998) Inducible phenotypic plasticity of the radula in Lacuna (Gastropoda: Littorinidae). Veliger 41:201-204

Padilla DK (2001) Food and environmental cues trigger an inducible offence. Evol Ecol Res 3:15-25

* Padilla DK, Dittman DE, Franz J, Sladek R (1996) Radular production rates in two species of Lacuna Turton (Gastropoda: Littorinidae) (1996). J Molluscan Stud 62:275-280

Pasanen AP, Kalliokoski P, Pasanen P, Jantunen MJ, Nevalainen A (1991) Laboratory studies on the relationship between fungal growth and atmospheric temperature and humidity. Environ Int 17:225-228

Pennings S, Bertness MD (2001) Salt marsh communities. In: Bertness MD, Gaines S, Hay M (eds) Marine community ecology. Sinauer, Sunderland, MA, p 289-316

Polis GA, Strong DR (1996) Food web complexity and community dynamics. Am Nat 147:813-846

Prideaux GJ, Ayliffe LK, DeSantis LRG, Schubert BW, Murray $\mathrm{PF}$, Gagan MK, Cerling TE (2009) Extinction implications of a chenopod browse diet for a giant Pleistocene kangaroo. Proc Natl Acad Sci USA 106:11646-11650

R Core Team (2015) RStudio: integrated development for R. RStudio, Boston, MA

Raia P, Carotenuto F, Meloro C, Piras P, Pushkina D (2010)

Editorial responsibility: Antony Underwood,

Sydney, New South Wales, Australia
The shape of contention: adaptation, history, and contingency in ungulate mandibles. Evolution 64:1489-1503

Reid DG, Mak YM (1999) Indirect evidence for ecophenotypic plasticity in radular dentition of Littoraria species (Gastropoda: Littorinidae). J Molluscan Stud 65:355-370

Scheltema AH, Kerth K, Kuzirian AM (2003) Original molluscan radula: comparisons among Aplacophora, Polyplacophora, Gastropoda, and the Cambrian fossil Wiwaxia corrugata. J Morphol 257:219-245

Schneider CA, Rasband WS, Eliceiri KW (2012) NIH Image to Image J: 25 years of image analysis. Nat Methods 9: 671-675

Sharp SJ, Angelini C (2016) Whether disturbances alter salt marsh soil structure dramatically affects Spartina alterniflora recolonization rate. Ecosphere 7:e01540

Sigwart JD, Carey N (2014) Grazing under experimental hypercapnia and elevated temperature does not affect the radula of a chiton (Mollusca, Polyplacophora, Lepidopleurida). Mar Environ Res 102:73-77

Silliman BR, He Q (2018) Physical stress, consumer control, and new theory in ecology. Trends Ecol Evol 33:492-503

Silliman BR, Newell S (2003) Fungal-farming in a snail. Proc Natl Acad Sci USA 100:15643-15648

Silliman BR, Zieman JC (2001) Top-down control of Spartina alterniflora production by periwinkle grazing in a Virginia salt marsh. Ecology 82:2830-2845

* Silliman BR, van de Koppel J, Bertness MD, Stanton LE, Mendelssohn IA (2005) Drought, snails, and large-scale die-off of southern U.S. salt marshes. Science 310: 1803-1806

WWang H, Fu R, Kumar A, Li W (2010) Intensification of summer rainfall variability in the Southeastern United States during recent decades. J Hydrometeorol 11:1007-1018

*War AR, Paulraj MG, Ahmad T, Buhroo AA, Hussain B, Ignacimuthu S, Sharma HC (2012) Mechanisms of plant defense against insect herbivores. Plant Signal Behav 7 : 1306-1320

*Watanabe JT, Young CM (2006) Feeding habits and phenotypic changes in proboscis length in the southern oyster drill, Stramonita haemastoma (Gastropoda: Muricidae), on Florida sabellariid worm reefs. Mar Biol 148:1021-1029

Williams DE, Miller MW (2005) Coral disease outbreak: pattern, prevalence and transmission in Acropora cervicornis. Mar Ecol Prog Ser 301:119-128

Wilson KA (1989) Ecology of mangrove crabs: predation, physical factors, and refuges. Bull Mar Sci 44:263-273

Windham L, Weis JS, Weis P (2001) Patterns and processes of mercury release from leaves of two dominant salt marsh macrophytes, Phragmites australis and Spartina alterniflora. Estuaries 24:787-795

Submitted: October 24, 2018; Accepted: April 23, 2019

Proofs received from author(s): June 7, 2019 